\title{
Gating System Design Solutions for Casting Defects from Pouring
}

\author{
ADEFUYE, O. A. ${ }^{1 *}$, ORISALEYE J. I. ${ }^{2}$, LAWAL O. I. ${ }^{1}$, FADIPE, O. L. ${ }^{1}$ \\ ${ }^{1}$ Department of Mechanical Engineering, Lagos State University, Epe, Nigeria. \\ ${ }^{2}$ Department of Mechanical Engineering, University of Lagos, Akoka, Nigeria \\ *Corresponding author: olusegun.adefuye@ lasu.edu.ng
}

Received: $19^{\text {th }}$ December 2019

Accepted: $5^{\text {th }}$ February 2020

Published: 31st March 2020

https://doi.org/10.47545/etrj.2020.5.1.057

\begin{abstract}
A recent study conducted by the authors, recording on site observations and grading responses to questionnaires by the 1 to 5 according to the Likert scale indicates that the gating practice in the foundries of research institutions and tertiary institutions in Lagos state is far from the best global practice. Some common errors, such as lack of knowledge and application of the critical flow velocity of the molten metal, prevention of flow stoppage across extensive horizontal planes with consequential non uniform liquid front. Lack of knowledge of the best types of pouring basins to use, Lack of knowledge on general filter types and usages among others were identified. This paper provides simple but highly effective solutions that do not warranty the purchase of new facilities. It is important to advance the knowledge of our training institutes especially as they are responsible for the training of our present and future foundry work force. The capability of our foundries is improved by the quality of the work force and this paper is hoped will contribute in no small measure to the capability of our foundries by improving the knowhow of the work force.
\end{abstract}

Keywords: Casting defects, foundry practices, gating systems, sand casting

\section{INTRODUCTION}

Production of castings essentially involves the following steps, pattern making, molding, pouring, fettling and testing. Of all these processes pouring is the shortest and most destructive. One mechanism by which pouring wreak havoc on castings is the entrainment of biofilms [6], these are metal oxide films formed by folding of dry surface of a metal oxide film over another dry surface of the metal oxide film. The surfaces of the oxide films do not bond to each oxide as could have happened if the surfaces were wet. Thus, a bifilm constitutes a crack, and fracture of the casting would normally occur here in service. This occurs well below the fracture strength of the material as in an absence of a bifilm failure by fracture requires nucleation and propagation of crack but with the bifilm, a crack has already been nucleated and propagated to some extent. Only further propagation of the crack is required for the casting to fail. The bifilms are ceramics and therefore under stress, they are generally weaker than metals,

What made the bifilm more dangerous is that it is so thin that it could not be detected by $\mathrm{x}$-ray equipment which most foundries use in non-destructive testing of their castings. It is not a strange occurrence for a client to collect apparently sound casting from the foundry only to reach his place to discover that most of the castings are cracked. Occurrences like this have given castings the reputation of being unreliable. However, casting processes have been developed that are quite reliable and are preferred to forgings. It is interesting to know that in America today trains wheels are made by one of such processes, the Griffin process, as it has been found to produce castings of superior quality to forgings and that it did repeatedly. [5]

\section{GATING SYSTEM}

In order to produce sound castings, the geometry of all the components of the gating system is important. The geometry of each component contributes to controlling the flow of metal in the mold and this has a direct impact on the quality of the casting [4][8]. Choosing a suitable gating ratio is the first step in conventional design of a gating system. The suitable gating ratio should be appropriate for casting the selected alloy. The gating ratio is the ratio of the cross- 
sectional area of the sprue to that of the runner to that of the ingate. Skim bob, crocodile's teeth or filters are provided to prevent the metallic oxide from entering the mold cavity. Open or blind feeders, chills and fins are also used in gating systems.

It is desirable to convey the molten metal in a non-turbulent manner into all parts of the mold cavity. This should, ideally, be the purpose of the pouring basins (or cups), sprue, sprue well, runner and ingate. On the other hand, feeders, fins and chills serve to minimize the shrinkage that occurs during the phase change from liquid to solid. It is important to fill the gating system especially the runner, as fast as possible. A typical gating system showing its components is illustrated in Figure 1.

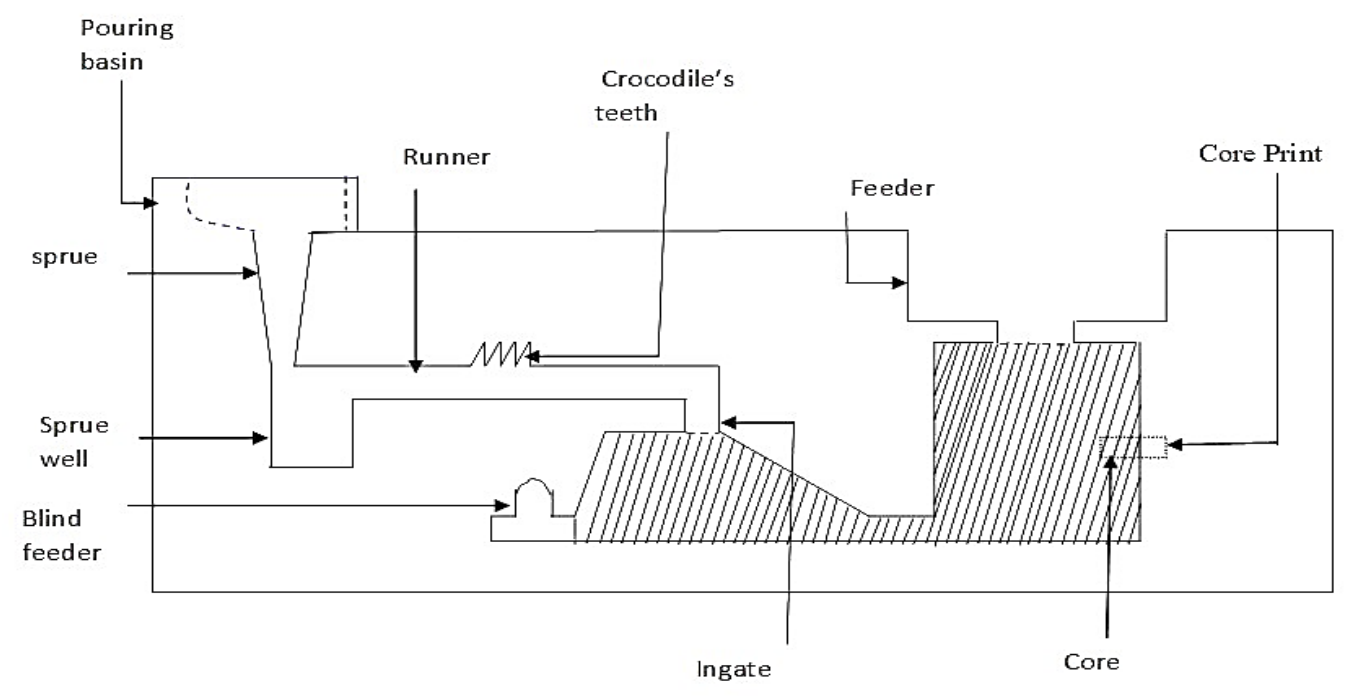

Figure 1: Components of the gating system; casting to be produced is indicated by hatched lines

\section{OVERVIEW OF THE RULES OF CASTING}

The discussion below is essentially based on five of the ten rules of casting developed by Professor John Campbell and relevant researches conducted after the rules were first published. The five rules were those that have direct implications on the gating systems. The rules are as follows [6].

1. Avoid turbulent entrainment

2. Avoid laminar entrainment of the surface film

3. Avoid bubble damage

4. Avoid shrinkage damage.

5. Avoid core blows

Of the four rules perhaps the one that has been most researched is the number one above. I refrain from saying it is the most important because if any of the rules are ignored then the casting will not be as sound as it should be and may have to be scrapped.

\section{CRITICAL VELOCITY TO PREVENT TURBULENT ENTRAINMENT}

The turbulence in rule 1 above is not the bulk turbulence usually determined by Reynolds number which is obtained from a comparison between inertial pressure and viscous pressure and expressed as:

$R e=v \rho d / v$

Rather the surface turbulence, indicated by the Weber numberWe, should be considered. Weber number is obtained from a comparison of the inertial pressure and surface tension pressure and is expressed as:

$W e=v^{2} \rho r / \gamma$ 
$v$ is the velocity of the molten metal of density $\rho$, viscosity $v$, and surface tension $\gamma$. The term, $d$, is the characteristic dimension of the flow path of the liquid. The term $r$ is the radius of curvature of a hemispherical surface deformation The work of Runyoro [11] showed that when molten aluminium in a mold moves at a velocity above $0.5 \mathrm{~m} / \mathrm{s}$, surface turbulence sets in. This velocity is called the critical velocity $v_{\text {crit }}$ is given as:

$v_{\text {crit }}=2(\gamma / r \rho)^{0.5}$

The critical velocity is the velocity above which there is an onset of free surface turbulence. Above this velocity, bifilms will be formed due to surface turbulence and entrained in the molten metal. The bifilms will then be carried by the molten metal into the mold cavity. Bifilms are essentially cracks in the castings and they reduce the strength of castings. Bifilms are very treacherous as they are so thin and are not detected by x-rays or any standard testing and inspection techniques except by electron microscopy. Therefore, the only way to prevent the formation of bifilms is to control the production process and one important way to achieve this is to design the gating system such that the mould is filled without significant surface turbulence. Researches [6] have shown that the critical velocity for light metals is about $5.5 \mathrm{~m} / \mathrm{s}$ and for dense metals such as copper and ferrous alloys, the critical velocity is about $4.5 \mathrm{~m} / \mathrm{s}$. Generally, a Weber number of 0.2 to 0.8 is acceptable.

Returning waves cause entrainment of bifilms and gases [9]. Usage of by-flows and slot gating will reduce the entrainment of gases potentially leading to bubble damage. Also, using the real-time x-ray machine thick gating systems have been shown to fill half the mold cavity or more before the runner is filled. Thus, thick runners encourage the entrainment of gases and oxides. In order to avoid both turbulent and laminar entrainment, it has been argued that the molten metal front must always keep moving forward. This is the no-stoppage no-retreat condition [6]. Reilly et al studied geometries of gating systems and observed among other things, that: it is impossible for the tranquil state to be achieved without a hydraulic jump and its inherent dissipation of energy; the trigger for an hydraulic jump to occur within a cross runner is the back wave (also called returning wave); and the use of a filter is required to initiate tranquil flow for a single pass system in the tranquil regime [9].

\section{CASTING PROBLEMS AND SOLUTIONS}

\subsection{Casting Problems}

Most castings are destroyed during the process of filling the mold with the molten metal. Often, this is not the fault of the pourer or pouring system but is attributable to the gating systems. This has also been found to be true of research and training institutes in Lagos state [2]. In fact, an attribute of a sound gating system is that it controls the way the mold cavity is filled independent of the pourer [6].

\subsection{Gating System Design Solutions}

In the past three decades, the science of casting underwent significant changes mainly due to the work done at the Interdisciplinary Research Centre (IRC) for the development of materials for high technical application at the School of Metallurgy and Materials in the University of Birmingham. The Centre also houses a European Centre of Excellence in casting technology. Using a real-time $\mathrm{x}$-ray equipment to enhance studies, Solutions proposed to the casting problems do not, interestingly, include purchasing of new equipment or machines. The proposed solutions and the theory behind them are presented in this section. Based on researches published within the last thirty years, especially those in which real-time x-ray machines were used to study the flow of molten metals inside synthetic sand molds, Gating components were optimized and newly developed charts and methods were used for the calculation of the dimensions of the gates. It was shown that the prevention of surface turbulence which was not considered as a factor in the conventional design of the gating system is perhaps the most important factor that should be considered especially, in light alloys casting.

Bottom gating: There are serious implications of the consideration of the critical velocity on gating systems. It is easily shown that for molten metal falling under gravity (which applies to gravity filling of molds), the minimum height through which dense alloys, aluminium and light alloys will fall before they achieve their critical velocity is respectively $10 \mathrm{~mm}, 12.5 \mathrm{~mm}$, and $15 \mathrm{~mm}$ respectively. These heights uncannily tally with the size of the sessile drops of the molten alloys. The heights are so small that it is impossible to produce a top gated casting that will be free of bifilms. Therefore, top gating, in spite of all its traditional advantages, is not recommended for the production of sound castings for technical applications. This is also the reason that makes it necessary to place patterns in the mold such 
that the smallest dimension is made the height. The sand casting rules recently put together by Sama and Guha [12] also does not recommend top gating. The work of Green and Campbell [7] using Weibull analysis showed clearly that generally bottom gated castings are stronger and much more reproducible than top gated castings. Side gating is also not recommended. Bottom gating is preferred and recommended but a filter must be used near the runner's entrance to slow down the molten metal to a velocity below the critical velocity. The metal must after coming out of the filter always move up and never fall. If the metal falls inside the mold through a distance sufficiently small that its velocity is lower than the critical velocity, it is possible to form and entrain bifilms by 'the waterfall effect' for example. This is one of the mechanisms by which laminar entrainment occurs.

Pouring basins and cups: The easiest pouring basin to mold and perhaps the most commonly used is the conical cup. It is however the worst in performance for so many reasons. It sucks in air into the molten metal which leads to gaseous and oxide inclusions. The way the mold is filled depends on which part of the conical flow the molten metal hits making the casting irreproducible. The offset step basin illustrated in Figure 2 is recommended [6][12], For best practice, it is to be used with a stopper.

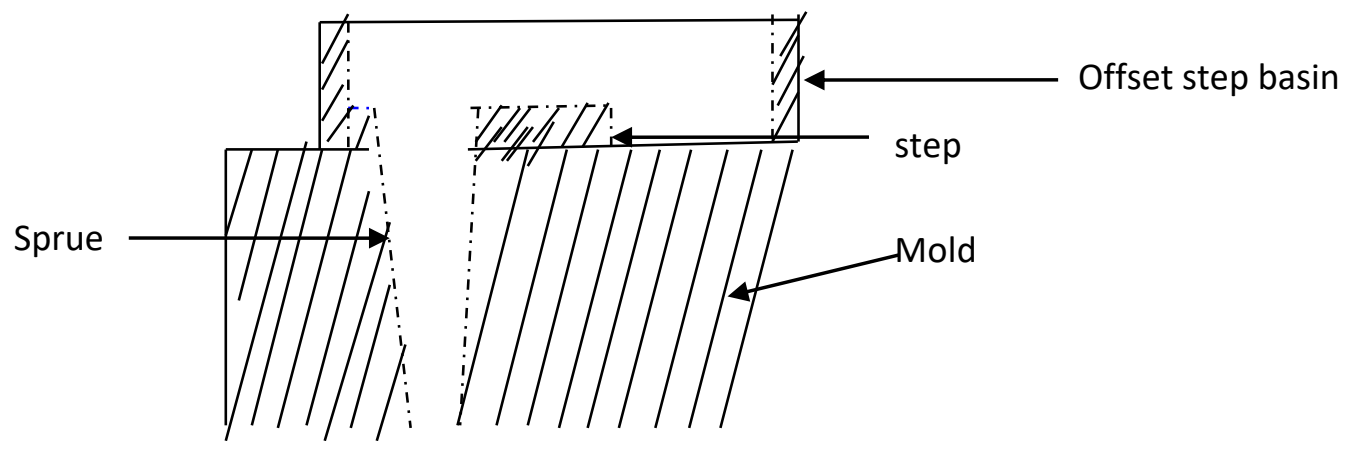

Figure 2 Offset step basin

The step of the offset step basin prevents the first (earliest) molten metal to reach the basin from going directly into the mold. A stopper will allow molten metal to fill the basin up to the desired level after which the stopper floats up or is removed. This promotes quick filling of the mold at a constant pressure head throughout the pouring stage

Sprues: The tapered sprue is favored as both the reverse tapered sprue and the untapered or parallel-sided sprue will encourage aspiration of air into the molten metal. The sprue taper should hug the metal without compressing it. It is termed naturally tapered sprue. [6][12]

Sprue wells: The sprue well does not serve any useful purpose and it is economical not to use it. A sprue that will curve into the runner was suggested by Sama and Manogharan [12]. They later developed a parabolic sprue [13], which performs satisfactorily but it requires the use of a 3D sand printing machine to produce it. However a filter positioned close to the sprue exit will cause the molten metal to enter the runner at the appropriate speed with a uniform front.

Runners: Slot runners are preferred. Runners are to be designed such that it fills quickly and the velocity of the metal reduces steadily from the runner entrance to the ingate. It has been shown that castings produced using pressurized system is inferior to those produced by unpressurised system [3].

Dross traps: Dross traps such as crocodile's teeth, and blind ends do not perform really as expected and are not recommended. Skim bobs have to be properly designed and molded to be effective. The know-how of skim bobs is not widespread. They are often designed and molded wrongly and are therefore not effective [6]. Filters used appropriately perform better than all other dross traps. The ceramic foam filter is considered the best because it also slows down the liquid metal passing through it and the molten metal emerges from it with a uniform front and at a 
velocity much lower than the velocity with which it entered the filter. This is attributable to the tortuous path of the pores the molten metal has to flow through in the filter.

Feeders: The feeder must be designed to satisfy the six rules of feeding, [5]. It is difficult to satisfy all the six rules which are the reason for a zeroth law of feeding which states that; do not feed, unless it is absolutely necessary. One basic result of the consideration of one of the rules of feeding, the pressure gradient requirement is that every blind riser must be vented otherwise a blind feeder may end up sucking molten metal from the casting instead of feeding it. Also, a new concept of feeding has been developed. Here the feeder and the casting are not considered separately, they are considered as a whole so instead of considering feeders that will solidify later than the casting, feeders that will solidify at the same time as the whole casting (i.e casting and feeders ) are considered

By-flows: These are devices that allow the first metal through the runner to bypass ingate(s). these prevent returning waves that promote turbulence in the runner. The work of Adefuye [1] shows that using whistlers (a form of by flows) increases the fluidity of aluminium-silicon casting alloys and its reproducibility significantly.

Cores: Cores are not to be bonded with clay and they should be properly vented in order to avoid core blow

Ingates: Ingates have to be positioned above the runner so that the runner will be completely filled before the molten metal starts filling the mold cavity. Its dimensions should satisfy the junction criteria and the transverse velocity must be sufficiently low to prevent surface turbulence and the accompanying bifilms.

\section{FURTHER WORK}

Having understood some mechanisms by which entrainment occurred in the mold, it was then possible to model the flow of liquid metal and attendant entrainment activities in the mold. A detailed review of the state of modeling entrainment was given by Reilly et al [10]. They noted that though the modeling of entrainment defect is in the infancy stage, some of the models available in the market show some promise though each had its weak points and concluded that the development of quantitative defect modeling techniques is difficult and complex. It is however of great industrial significance, and therefore further research is urgently required

\section{CONCLUSION}

The flow of metal through the gating system is much more understood now than before, Effective solutions to some common errors observed in the gating practices of foundries in Lagos state were explained. These solutions will not warrant the purchase of new facilities.

\section{REFERENCES}

[1] Adefuye O. A. (1997). the fluidity of Al-Si casting alloys,(Doctoral dissertation PhD. Thesis University of Birmingham)

[2] Adefuye, O. A., Orisaleye, J. I., Lawal, O. I., \& Fadipe, O. L. (2019, December). Gating Practices in Nigerian Research and Training Institutes: Case Study of Lagos State. In Journal of Physics: Conference Series (Vol. 1378, No. 3, p. 032095). IOP Publishing.

[3] Akinlabi, O., and Ayodele, A. (2015). EFFECTS OF GATING SYSTEM DESIGN ON TENSILE PROPERTIES OF CAST ALUMINIUM 6063 ALLOY. Acta Metallurgica Slovaca, 21(2), 135-141

[4] Anjo, V, and Khan R (2013) Gating System Design for Casting thin Aluminium Alloy (Al-Si) ,Plates Leonardo Electronic Journal of Practices and Technologies Issue 23, July- $\quad$ December 2013 . 51-62

[5] Campbell, J. (1991). Castings Butterworth.

[6] Campbell, J. (2004). Castings practice: the ten rules of castings. Elsevier. 
[7] Green, N. R., \& Campbell, J. (1993). Statistical distributions of fracture strengths of cast Al-7Si-Mg alloy. Materials Science and Engineering-A-Structural Materials, 173(1), 261-266.

[8] Ingle, P. D., and Narkhede, B. E. (2018). A literature survey of methods to study and analyze the gating system design for its effect on casting quality. Materials Today: Proceedings, 5(2), 5421-5429.

[9] Reilly, C., Green, N. R., \& Jolly, M. R. (2009). Surface oxide film entrainment mechanisms in shape casting running systems. Metallurgical and Materials Transactions B, 40(6), 850.

[10] Reilly, C., Green, N. R., \& Jolly, M. R. (2013). The present state of modeling entrainment defects in the shape casting process. Applied Mathematical Modelling, 37(3), 611-628.

[11] Runyoro, J., Boutorabi, S. M. A., \& Campbell, J. (1992). Critical gate velocities for film-forming casting alloys: a basis for process specification. AFS Trans, 37, 225-234.

[12] Sama, S. R. and Manogharan, G. P. (2017). Sand casting design rules. Pennsylvania State Univesrity.

[13] Sama, S. R., Badamo, T., Lynch, P., and Manogharan, G. (2019). Novel sprue designs in metal casting via 3D sand-printing. Additive Manufacturing, 25, 563-578. 